\title{
Surveillance for Antibiotic Resistance in Clostridium difficile Strains Isolated from Patients in a Tertiary Care Center
}

\author{
Meenakshi Singh ${ }^{1}$, Chetana Vaishnavi ${ }^{*}$, Safrun Mahmood ${ }^{2}$, Rakesh Kochhar ${ }^{1}$ \\ ${ }^{1}$ Department of Gastroenterology, Postgraduate Institute of Medical Education and Research, Chandigarh, \\ India \\ ${ }^{2}$ Department of Experimental Medicine and Biotechnology, Postgraduate Institute of Medical Education and \\ Research, Chandigarh, India \\ Email: ${ }^{*}$ cvaishnavi@rediffmail.com
}

Received 16 April 2015; accepted 13 May 2015; published 18 May 2015

Copyright @ 2015 by authors and Scientific Research Publishing Inc.

This work is licensed under the Creative Commons Attribution International License (CC BY). http://creativecommons.org/licenses/by/4.0/

(c) (i) Open Access

\begin{abstract}
Clostridium difficile is the major etiological agent of nosocomial diarrhea primarily precipitated by antimicrobial therapy. We prospectively investigated the antibiogram profile of $C$. difficile strains isolated from patients reporting to a tertiary care hospital in North India. Fecal samples obtained from 1110 suspected cases of $C$. difficile infection were cultured for isolation of $C$. difficile. Colonies suspected as those of $C$. difficile were identified by phenotypic and molecular methods. Antimicrobial susceptibility of $C$. difficile isolates for different classes of antibiotics was determined using the Epsilon test for vancomycin, metronidazole, clindamycin and ciprofloxacin. The fecal samples cultured for $C$. difficile belonged to $709(63.9 \%)$ males and $401(36.1 \%)$ females. The mean age of the patients was 38.7 years. $C$. difficile was cultured from $174(15.7 \%)$ of the total samples. Antibiotic resistance was largely observed towards clindamycin $(57.5 \%)$ and ciprofloxacin $(38.5 \%)$ but was significantly low towards metronidazole $(1.72 \%)$ and nil $(0 \%)$ towards vancomycin. C. difficile isolates had a high degree of resistance towards clindamycin and ciprofloxacin with low level of resistance to metronidazole and none towards vancomycin. Antibiogram surveillance of $C$. difficile will help for clinical practice and add to the epidemiological data of the organisms.
\end{abstract}

\section{Keywords}

Clostridium difficile, Cultural Identification, Antimicrobial Susceptibility, E-Test

\footnotetext{
${ }^{*}$ Corresponding author.
}

How to cite this paper: Singh, M., Vaishnavi, C., Mahmood, S. and Kochhar, R. (2015) Surveillance for Antibiotic Resistance in Clostridium difficile Strains Isolated from Patients in a Tertiary Care Center. Advances in Microbiology, 5, 336-345. 


\section{Introduction}

Clostridium difficile, a Gram-positive spore bearing, anaerobic toxigenic bacterium is the major etiological agent of nosocomial diarrhea and is frequently precipitated with antimicrobial therapy [1]. C. difficile infection (CDI) is associated with considerable morbidity, mortality and relapse among hospitalized patients across the globe [2] [3]. Metronidazole is the first line of therapy for CDI. This drug has been found to be effective in mild to moderate disease on the basis of its efficacy, cost and antimicrobial stewardship. In more severe cases of CDI, vancomycin has been shown to be superior to metronidazole [4].

According to a European survey of diagnostic methods for $C$. difficile identification, culture of the organism is performed only in a few countries [5]. This is because $C$. difficile is a fastidious organism and requires selective medium for its isolation. A variety of culture media like cefoxitin-cycloserine-fructose agar (CCFA) or C. difficile moxalactam norfloxacin [6] [7] are available for its isolation. CCFA was the initial formulation developed for isolation of $C$. difficile [6]. But $C$. difficile also grows easily on Columbia blood agar (CBA) at $37^{\circ} \mathrm{C}$ by 48 hours [8]. The addition of lysozyme or bile salts such as taurocholate to the medium facilitates the outgrowth of spores [9] [10].

Acquisition of resistance to clindamycin is considered as one of the mechanism whereby clonal strains of $C$. difficile emerge and predominate in healthcare environments. Historically, fluoroquinolone antimicrobial agents were considered as low risk for CDI. However, studies carried out later on indicated a shift in the risk associated with their use [11] [12]. Furthermore outbreaks in Canada and the United States during the last decade have been associated with fluoroquinolone exposure and the emergence of the fluoroquinolone resistant hypervirulent NAP1/BI/027 (North American Pulse Field type 1, Restriction Endonuclease Assay BI, Ribotype 027) strain [13].

Studies on antibiotic resistant pattern of $C$. difficile from developing countries are sparse. This is due to the lack of funding and facilities for anaerobic culture. Initially, the disk diffusion method was used for antibiotic susceptibility by workers in the field. Later on Epsilon test (E-test) became available and was found to be a reliable and easy-to-perform method for minimal inhibitory concentration (MIC) determination of C. difficile antibiotic susceptibility testing in diagnostic laboratories [14]. We performed a prospective study to investigate the antibiogram profile of $C$. difficile strains cultured from the fecal samples of patients suspected to have CDI.

\section{Materials and Methods}

The study was carried out at Post Graduate Institute of Medical Education and Research, a tertiary care center of North India. This hospital caters to different parts of North India viz. Chandigarh, Punjab, Haryana, Himachal Pradesh, Jammu and Kashmir, western parts of Uttar Pradesh and some parts of Rajasthan. The study was approved by the Institute Ethics Committee and was carried out from June 2012 to May 2014. A total of 1110 patients suspected to have CDI formed the basis of investigation. Informed consent was taken from all the patients or their wards.

\subsection{Laboratory Chemicals and Media Used in the Study}

All chemicals used were of analytical grade. Robertson's cooked meat media (RCM), Columbia blood agar, urea agar base, Brucella agar, esculin agar, esculin, urea, sodium taurocholate, sodium borohydride, citric acid and glucose were procured from HiMedia, Mumbai, India. Sodium bicarbonate, methylene blue, crystal violet, iodine, safranine, hydrochloric acid and p-dimethylaminobenzaldehyde were purchased from Central Drug House, New Delhi, India.

\subsection{Isolation and Phenotypic Identification of $C$. difficile}

Single fecal specimens collected from the patients in sterile containers with spoons (Stericol, HiMedia, India) were subjected to initial enrichment in RCM media overnight at $37^{\circ} \mathrm{C}$ in an anaerobic condition. Culture of $C$. difficile was done on CBA containing $0.1 \%$ sodium taurocholate and incubated anaerobically for $48 \mathrm{~h}$ at $37^{\circ} \mathrm{C}$ in an anaerobic jar. The fecal samples were also cultured on CBA after alcohol shock treatment to allow the survival of sporulating bacteria. Colonies suspected as $C$. difficile were further identified by Gram staining, ultraviolet fluorescence and by conventional biochemical reactions like indole test, urease test, lecithinase test, lipase test and bile esculin hydrolysis. 


\subsection{Molecular Identification of $C$. difficile}

The identity of isolates was further confirmed using polymerase chain reaction (PCR) primers for amplifying triose-phosphate isomerase (tpi) gene which is specific for C. difficile. C. perfringens 13124 MTCC (Microbial Type Culture Collection) obtained from Institute of Microbial Technology, Chandigarh, India served as the negative control. Briefly, DNA was isolated by phenol-chloroform method and PCR amplification was performed in a mastercycler (Eppendorf, Germany). The $20 \mu \mathrm{l}$ reaction mixture contained $1 \times$ PCR buffer $(50 \mathrm{mM} \mathrm{KCl}, 10$ $\mathrm{mM}$ Tris $\mathrm{HCl} \mathrm{pH}$ 8.3, $1.5 \mathrm{mM} \mathrm{MgCl}_{2}$ ), $0.2 \mathrm{mM}$ of $10 \mathrm{mM}$ each of dNTP, $1 \mathrm{pM}$ of $10 \mathrm{pM}$ oligonucleotide forward and reverse primers and $0.5 \mu \mathrm{l}$ of $1.0 \mathrm{U}$ Taq polymerase. Amplifications were carried out by initial denaturation at $94^{\circ} \mathrm{C}$ for $5 \mathrm{~min}$ followed by 25 cycles of $30 \mathrm{sec}$ at $94^{\circ} \mathrm{C}, 30 \mathrm{sec}$ at $50^{\circ} \mathrm{C}, 30 \mathrm{sec}$ at $72^{\circ} \mathrm{C}$, and a final extension step of $5 \mathrm{~min}$ at $72^{\circ} \mathrm{C}$. After amplification, the products were electrophoresed in $1.8 \%$ agarose gel containing $0.5 \mu \mathrm{g} / \mathrm{ml}$ ethidium bromide. The amplification gave a single product of 230-bp fragment in all C. difficile isolates as visualized under Gel Documentation System (Alpha Image, San Diego, USA).

\subsection{Antibiogram Profile}

Antimicrobial susceptibility of $C$. difficile isolates was determined using the E-test for vancomycin, metronidazole, ciprofloxacin and clindamycin. Breakpoint for vancomycin and metronidazole was defined by European Committee on Antimicrobial Susceptibility Testing (EUCAST) guidelines and for clindamycin and ciprofloxacin by Clinical Laboratories Standards Institute (CLSI). Briefly, the E-test was performed by inoculating the surface of pre-reduced Brucella Agar plates containing 5\% defibrinated sheep blood with 1 McFarland standard matched $C$. difficile inoculum. The inoculation was done with sterile cotton-tipped swabs dipped into the inoculum, pressed against the inside of the tube to remove excess fluid and streaked three times at $90^{\circ} \mathrm{C}$. The plates were incubated at $37^{\circ} \mathrm{C}$ for $48 \mathrm{~h}$ under anaerobic conditions, and the MIC were read directly from the test strip point where the growth inhibition zone intersected with the test strip in accordance with the manufacturer's instruction. Quality controls used were Clostridium perfringens MTCC 13124 and Streptococcus sp. MTCC 689 strains.

\section{Results}

During analysis the patients from whom fecal samples were obtained were categorized into the following four groups according to their age.

Pediatric Group: This group comprised of 189 patients in the pediatric age group of 2 - 18 years.

Young Adult Group: This group included 504 young adults in the age group $>18$ - 45 years.

Middle Age Group: This group involved 342 patients belonging to middle age of $>45$ - 65 years.

Geriatric Group: In the geriatric group, 75 patients above 65 years of age were included.

\subsection{Phenotypic Identification of $C$. difficile Isolates}

Colonies suspected as $C$. difficile had a characteristic horse-manure odor and appeared white to grey in color with irregular margins enhancing towards the streaked line (Figure 1(a)). The colonies gave yellow-green fluorescence under ultraviolet illumination (Figure 1(b)). Biochemical reactions showed 100\% of the isolates were indole negative, urease negative, lecithinase negative, lipase negative and bile esculin positive (Figure 2). Thus by phenotypic identification, C. difficile was isolated from 174 (15.7\%) of the 1110 fecal samples.

\subsection{Genotypic Confirmation of $C$. dificile Isolates}

All of the microbiologically identified C. difficile isolates (100\%) were further confirmed genotypically by the presence of housekeeping tpi gene, which is more discriminatory than 16S ribosomal DNA for the identification of various species within the genus Clostridium (Figure 3). C. difficile positivity was 13.8\% in Pediatric Group, 17.0\% in Young Adult Group, 15.0\% in Middle Age Group and 14.7\% in Geriatric Group.

\subsection{Antibiogram Profile of Clinical Isolates}

The MIC breakpoint for isolates resistant to vancomycin and metronidazole was taken as $>2 \mathrm{mg} / \mathrm{L}$ according to EUCAST guidelines. Strains with MIC breakpoint of $\geq 0.025 \mathrm{mg} / \mathrm{L}$ for ciprofloxacin and MIC breakpoint of 


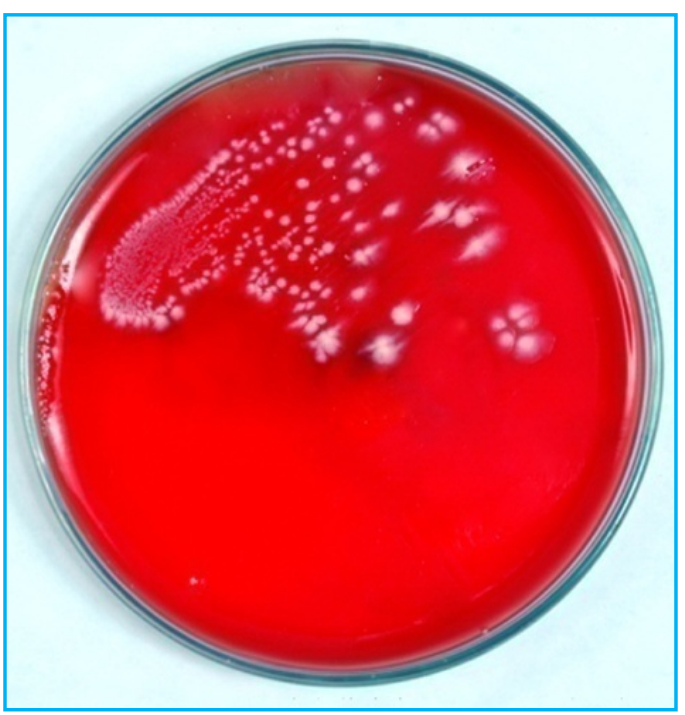

(a)

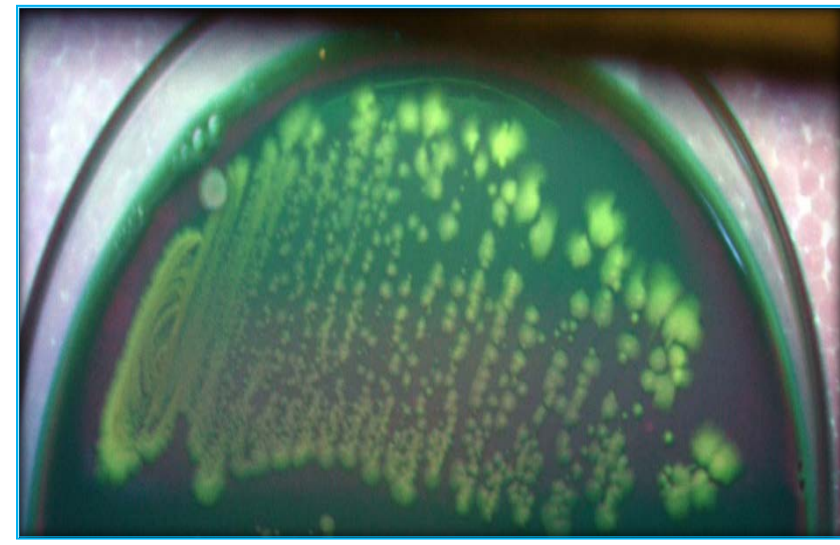

(b)

Figure 1. (a) Colonies of C. difficile on CBA; (b) Colonies of C. difficile fluoresce under UV light.

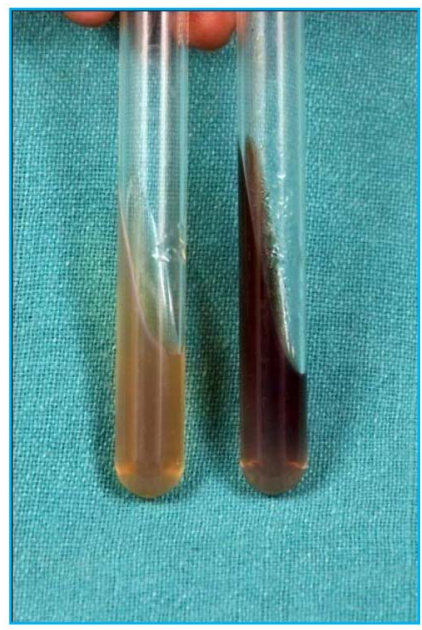

Streptococcus sp. MTCC 689 negative for bile esculin hydrolysis test
C. difficile isolate positive for bile esculin hydrolysis test

Figure 2. Bile esculin test.

$\geq 0.002 \mathrm{mg} / \mathrm{L}$ for clindamycin were respectively considered clinically resistant according to CLSI guidelines. The MIC range for vancomycin, metronidzole and ciprofloxacin was $0.016-256 \mathrm{mg} / \mathrm{L}$ while for clindamycin, it was $0.002-0.032 \mathrm{mg} / \mathrm{L}$. All of the isolates (100\%) were sensitive to vancomycin, $1.72 \%$ was resistant to metronidazole, 52.9\% were resistant to clindamycin and 33.9\% resistant to ciprofloxacin (Figure 4(a), Figure 4(b), Figure 5).

\section{Discussion}

Although the need for $C$. difficile epidemiology is urgent, not much progress has been reported due to the lack of awareness and surveillance against CDI in many parts of India. The main reason to identify C. difficile is the emergence of the hypervirulent strains leading to outbreaks of infection associated with an increased severity of disease and significant mortality [15]. Another reason is to know the development of antimicrobial resistance of the pathogen to the commonly used CDI specific drugs. Thus, it becomes necessary to culture the organism and 


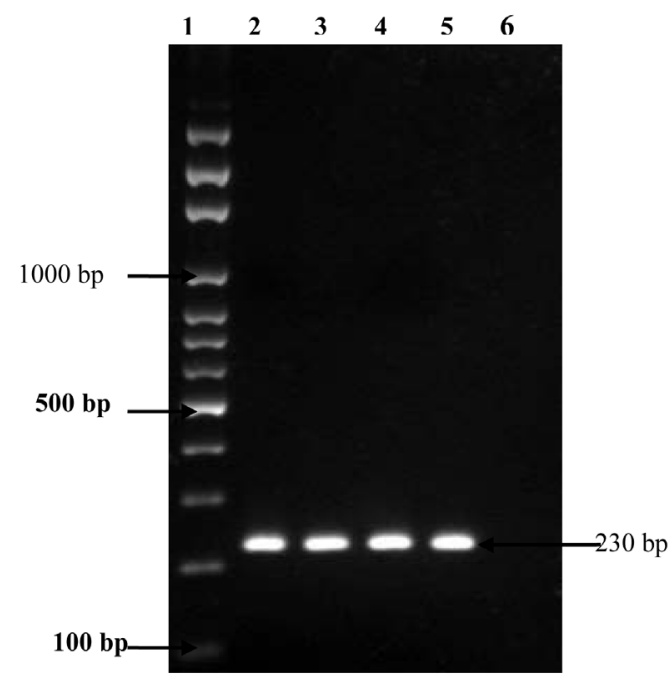

Lane 1-100 bp ladder

Lane 2-ATCC 43255 C. difficile positive control Lane 3-5 Samples

Lane 6-Negative control

Figure 3. PCR amplification of tpi gene with 230 bp amplicon size.

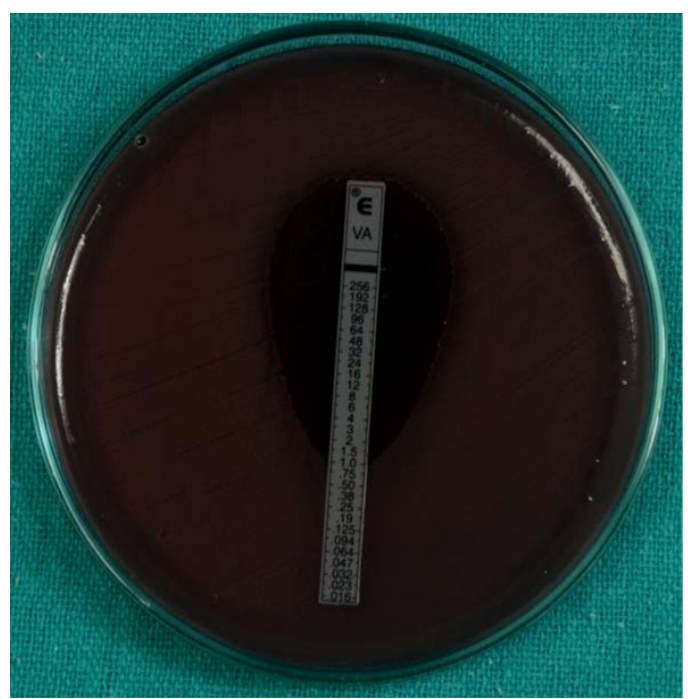

(a)

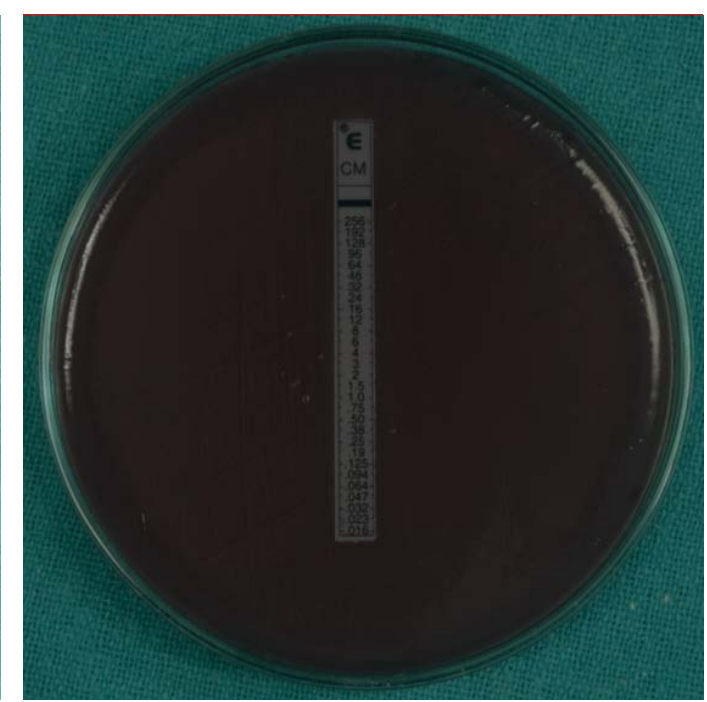

(b)

Figure 4. Antibiotic sensitivity by Epsilon test. (a) Vancomycin; (b) Clindamycin.

perform its antibiogram profile. As per the recommendations by both the Society for Healthcare Epidemiology of America and the Infectious Diseases Society of America, C. difficile culture on CCFA medium should contain a germinant like lysozyme or taurocholate for itsisolation [16]. However, Clostridia other than $C$. difficile are also able to grow over it [17]. In the present study fecal samples were enriched initially by using Robertson's cooked meat media and further cultured on CBA media along with sodium taurocholate for the germination of $C$. difficile spores. To increase the specificity for growth of spore producing $C$. difficile, fecal samples were also subjected to alcohol shock. Culture enabled the detection of C. difficile in $15.7 \%$ of a total of 1110 fecal specimens which was further confirmed by molecular method. Toxigenic C. difficile was found in $54.6 \%$ of the isolates by ELISA. Toxin positive C. difficile was present in 53.8\% in Pediatric Group, 53.5\% in Young Adult 


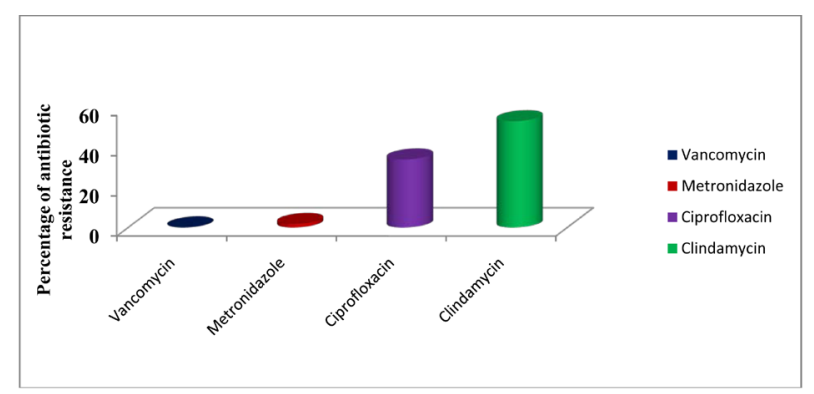

Figure 5. Percentage of antibiotic resistance among different drugs against $C$. difficile.

Group, 55.0\% in Middle Age Group and 63.6\% in Geriatric Group. However, C. difficile toxin positivity was not significant ( $p>0.05$ ) among any group (data not shown).

There is very little literature of $C$. difficile culture from India due to the lack of technology in culturing this anaerobic pathogen. Gupta and Yadav [18] reported isolation of C. difficile from 25.3\% of diarrheal patients of all age groups. Ayyagari et al. [19] reported the presence of C. difficile in $22.6 \%$ stool specimens obtained from cases of antibiotic associated colitis. Niyogi et al. [20] isolated C. difficile from $8.4 \%$ fecal samples in pediatricage group. Dutta et al. [21] detected C. difficile in 8.4\% of fecal samples of children between 0 - 14 years of age. Gogate et al. [22] isolated C. difficile in 7.2\% of children in the age group 5 - 12 years with antibiotic associated diarrhea. In general, the prevalence of CDI in India has been reported to be $15 \%-30 \%$ in pediatric and adult patients receiving antibiotics [21] [23]-[26].

It is well known that CDI is largely associated with the intake of antibiotics. The widespread use of antibiotics in most Asian countries is poorly regulated. Reports surveyed on Southeast Asian countries found that $47 \%$ of pneumonia cases do not receive an appropriate antibiotic, 54\% of diarrhea cases are unnecessarily treated with antibiotics, and $40 \%$ of antibiotics are prescribed in under-dose [27]. A recent study by Vishwanath et al. [26] reported third-generation cephalosporins or beta-lactam/beta-lactamase inhibitor antibiotics as the risk factor for precipitation of CDI. Development of resistance in bacteria is a natural phenomenon, though excessive usage of antibiotic can also exert a selective pressure, leading to reduced susceptibility and ultimately antimicrobial resistance [28]. The two major antibiotics—vancomycin and metronidazole-are the mainstays for the treatment of mild to moderate CDI [29] [30]. Metronidazole is considered to be the drug of choice for CDI because of its low cost, good activity against $C$. difficile, favorable pharmacokinetic and pharmacodynamic properties, and minor adverse effects. Vancomycin is used to treat severe cases of CDI. Due to limited treatment options for CDI, any resistance or reduced susceptibility to these drugs is a significant public health concern [31] [32].

There are several reports from Europe, North America and the Far East on the emergence of multidrug resistance amongst $C$. difficile [33] [34]. Reports of vancomycin and metronidazole resistance are rare and sporadic [35]-[37]. In some studies, resistance towards metronidazole has been reported up to 9\% [36] [38]. Pelaez et al. [37] [39] reported C. difficile isolates with intermediate resistance to vancomycin (3.1\%) and metronidazole (6.3\%) Several other studies have reported decreased sensitivity of NAP1/BI/027 to metronidazole and increased recurrence of CDI in patients treated with metronidazole and vancomycin [40] [41]. In the present study, no resistance to vancomycin was observed in any of the clinical isolates tested, but resistance to metronidazole was $1.3 \%$. The low resistance seen for metronidazole and none for vancomycin could be due to the absence of NAP1/BI/027 strains in this region of study. Though very little resistance is known against $C$. difficile specificdrugs, there is a definite need for periodic monitoring of any emergence of vancomycin and metronidazole resistance in C. difficile.

Apart from vancomycin and metronidazole, the other two drugs investigated for antibiotic profile in the present study were ciprofloxacin and clindamycin as an increase in fluoroquinolone [42] and clindamycin resistant strains [43] have been noted in several other countries. Hypervirulent strains of $C$. difficile particularly NAP1/BI/027 has shown multiple drug resistance towards clindamycin, moxifloxacin and rifampin [44]. Epidemics caused due to NAP1/BI/027 strains have been characterized by recently evolved resistance to fluoroquinolone-the antibiotic currently in wide use [45].

In the present study a high degree of resistance was observed towards ciprofloxacin (33.9\%) and clindamycin (52.9\%). The high degree of resistance towards ciprofloxacin and clindamycin among the isolates in this study 
correlates well with that of others studies. Huang et al. [42] reported in vitro activity of ciprofloxacin to be moderate or poor against $C$. difficile. High level of resistance against ciprofloxacin was reported against epidemic strains of $C$. difficile [11] [12]. Borgmann et al. [46] reported that the increased use of ciprofloxacin by outpatients contributed to increased numbers of CDI. Resistance to clindamycin has been reported to be $>50 \%$ worldwide [44]. The utility of antibiogram profiling has already been proven useful with previously unseen fluoroquinolone resistance [47]. Resistance to these drugs highlights the emergence of a new strain [48] and a particular profile of antibiogram is also indicative of the hypervirulent PCR ribotype 027 strain [49]. It is also proposed that $C$. difficile may acquire drug resistance genes due to the presence of a high number of transposons (11\%) within the genome [33], thereby allowing the genes to be acquired resulting in enhanced survival of the organism both within the gut and outside the gut. Mooyottu et al. [50] studied the genome characterization in $C$. difficile isolates and documented the presence of several antibiotic resistance genes and mobile elements that can potentially contribute to generation of multidrug resistant toxigenic $C$. difficile by horizontal gene transfer. Antibiogram profiling for $C$. difficile is thus a valuable tool in the surveillance of antibiotic resistance as shown in the current study.

\section{Conclusion}

C. difficile isolates had a high degree of resistance towards clindamycin and ciprofloxacin with low level of resistance to metronidazole and none towards vancomycin. Antibiogram surveillance of $C$. difficile will help for clinical practice and add to the epidemiological data of the organisms.

\section{Acknowledgements}

Mr. Gurinder Singh Cheema is acknowledged for technical assistance. This work was supported by the Council of Scientific and Industrial Research, New Delhi, India (Grant No. 27 (259)/12).

\section{Transparency Declaration}

There is no conflict of interest to report.

\section{References}

[1] Vaishnavi, C., Bhasin, D.K., Kochhar, R. and Singh, K. (2000) Clostridium difficile Toxin and Faecal Lactoferrin Assays in Adult Patients. Microbes and Infection, 2, 1827-1830. http://dx.doi.org/10.1016/S1286-4579(00)01343-5

[2] Burke, K.E. and Lamont, J.T. (2014) Clostridium difficile Infection: A Worldwide Disease. Gut and Liver, 8, 1-6. http://dx.doi.org/10.5009/gnl.2014.8.1.1

[3] Jalali, M., Khorvash, F., Warriner, K. and Weese, J.S. (2012) Clostridium difficile Infection in an Iranian Hospital. BMC Research Notes, 5, 159. http://dx.doi.org/10.1186/1756-0500-5-159

[4] Zar, F.A., Bakkanagari, S.R., Moorthi, K.M. and Davis, M.B. (2007) A Comparison of Vancomycin and Metronidazole for the Treatment of Clostridium difficile-Associated Diarrhea, Stratified by Disease Severity. Clinical Infectious Diseases, 45, 302-307. http://dx.doi.org/10.1086/519265

[5] Barbut, F., Delmee, M., Brazier, J.S., Petit, J.C., Poxton, I.R., Rupnik, M., Lalande, V., Schneider, C., Mastrantonio, P., Alonso, R., Kuipjer, E., Tvede, M. and The ESCMID Study Group on Clostridium difficile (ESGCD) (2003) A European Survey of Diagnostic Methods and Testing Protocols for Clostridium difficile. Clinical Microbiology and Infection, 9, 989-996. http://dx.doi.org/10.1046/j.1469-0691.2003.00683.x

[6] Arroyo, L.G., Rousseau, J., Willey, B.M., Low, D.E., Staempfli, H., McGeer, A. and Weese, J.S. (2005) Use of a Selective Enrichment Broth to Recover Clostridium difficile from Stool Swabs Stored under Different Conditions. Journal of Clinical Microbiology, 43, 5341-5343. http://dx.doi.org/10.1128/JCM.43.10.5341-5343.2005

[7] George, W.L., Sutter, V.L., Citron, D. and Finegold, S.M. (1979) Selective and Differential Medium for Isolation of Clostridium difficile. Journal of Clinical Microbiology, 9, 214-219.

[8] Perry, J.D., Asir, K., Halimi, D., Orenga, S., Dale, J., Payne, M., Carlton, R., Evans, J. and Gould, F.K. (2010) Evaluation of a Chromogenic Culture Medium for Isolation of Clostridium difficile within 24 Hours. Journal of Clinical Microbiology, 48, 3852-3858. http://dx.doi.org/10.1128/JCM.01288-10

[9] Wilcox, M.H., Fawley, W.N. and Parnell, P. (2000) Value of Lysozyme Agar Incorporation and Alkaline Thioglycollate Exposure for the Environmental Recovery of Clostridium difficile. Journal of Hospital Infection, 44, 65-69. http://dx.doi.org/10.1053/jhin.1999.0253 
[10] Wren, M. (2010) Clostridium difficile Isolation and Culture Techniques Methods. Journal of Molecular Biology, 646, 39-52. http://dx.doi.org/10.1007/978-1-60327-365-7_3

[11] Drudy, D., Kyne, L., O’Mahony, R. and Fanning, S. (2007) GyrA Mutations in Fluoroquinolone-Resistant Clostridium difficile PCR-027. Emerging Infectious Diseases, 13, 504-505. http://dx.doi.org/10.3201/eid1303.060771

[12] Muto, C.A., Pokrywka, M., Shutt, K., Mendelsohn, A.B., Nouri, K., Posey, K., Roberts, T., Croyle, K., Krystofiak, S., Patel-Brown, S., Pasculle, A.W., Paterson, D.L., Saul, M. and Harrison, L.H. (2005) A Large Outbreak of Clostridium difficile-Associated Disease with an Unexpected Proportion of Deaths and Colectomies at a Teaching Hospital Following Increased Fluoroquinolone Use. Infection Control and Hospital Epidemiology, 26, 273-280. http://dx.doi.org/10.1086/502539

[13] Drudy, D., Quinn, T., O’Mahony, R., Kyne, L., O’Gaora, P. and Fanning, S. (2006) High-Level Resistance to Moxifloxacin and Gatifloxacin Associated with a Novel Mutation in GyrB in Toxin-A-Negative, Toxin-B-Positive Clostridium difficile. Journal of Antimicrobial Chemotherapy, 58, 1264-1267. http://dx.doi.org/10.1093/jac/dkl398

[14] Poilane, I., Cruaud, P., Torlotin, J.C. and Collignon, A. (2000) Comparison of the E-Test to the Reference Agar Dilution Method for Antibiotic Susceptibility Testing of Clostridium difficile. Clinical Microbiology and Infection, 6, 155156. http://dx.doi.org/10.1046/j.1469-0691.2000.00034-4.x

[15] Kuijper, E.J., Barbut, F., Brazier, J.S., Kleinkauf, N., Eckmanns, T., Lambert, M.L., Drudy, D., Fitzpatrick, F., Wiuff, C., Brown, D.J., Coia, J.E., Pituch, H., Reichert, P., Even, J., Mossong, J., Widmer, A.F., Olsen, K.E., Allerberger, F., Notermans, D.W., Delmée, M., Coignard, B., Wilcox, M., Patel, B., Frei, R., Nagy, E., Bouza, E., Marin, M., Åkerlund, T., Virolainen-Julkunen, A., Lyytikäinen, O., Kotila, S., Ingebretsen, A., Smyth, B., Rooney, P., Poxton, I.R. and Monnet, D.L. (2008) Update of Clostridium difficile Infection Due to PCR Ribotype 027 in Europe 2008. Euro Surveillance, 13, Article ID: 18942.

[16] Cohen, S.H., Gerding, D.N., Johnson, S., Kelly, C.P., Loo, V.G., McDonald, L.C., Pepin, J. and Wilcox, M.H., Society for Healthcare Epidemiology of America and Infectious Diseases Society of America (2010) Clinical Practice Guidelines for Clostridium difficile Infection in Adults: 2010 Update by the Society for Healthcare Epidemiology of America (SHEA) and the Infectious Diseases Society of America (IDSA). Infection Control and Hospital Epidemiology, 31, 431-455. http://dx.doi.org/10.1086/651706

[17] Lee, K., Yong, D., Yum, J., Sohn, Y.S. and Chong, Y. (2000) Modification of Cycloserine Cefoxitin Fructose Agar to Suppress Growth of Yeasts from Stool Specimens. Anaerobe, 6, 269-271. http://dx.doi.org/10.1006/anae.2000.0355

[18] Gupta, U. and Yadav, R.N. (1985) Clostridium difficile in Hospital Patients. Indian Journal of Medical Research, 82, 398-401.

[19] Ayyagari, A., Sharma, P., Venkateswarlu, Mehta, S. and Agarwal, K.C. (1986) Prevalence of Clostridium difficile in Pseudomembranous and Antibiotic Associated Colitis in North India. Journal of Diarrhoeal Diseases Research, 4, 157-160.

[20] Niyogi, S.K., Dutta, P., Dutta, D., Mitra, U. and Sikdar, S. (1991) Clostridium difficile and Its Cytotoxin in Hospitalized Children with Acute Diarrhea. Indian Pediatrics, 28, 1129-1132.

[21] Dutta, P., Niyogi, S.K., Mitra, U., Rasaily, R., Bhattacharya, M.K., Chakraborty, S. and Mitra, A. (1994) Clostridium difficile in Antibiotic Associated Pediatric Diarrhea. Indian Pediatrics, 31, 121-126.

[22] Gogate, A., De, A., Nanivadekar, R., Mathur, M., Saraswathi, K., Jog, A. and Kulkarni, M.V. (2005) Diagnostic Role of Stool Culture and Toxin Detection in Antibiotic Associated Diarrhoea Due to Clostridium difficile in Children. Indian Journal of Medical Research, 122, 518-524.

[23] Dhawan, B., Chaudhry, R. and Sharma, N. (1999) Incidence of Clostridium difficile Infection: A Prospective Study in an Indian Hospital. Journal of Hospital Infection, 43, 275-280. http://dx.doi.org/10.1016/S0195-6701(99)90423-1

[24] Vaishnavi, C., Kochhar, R., Bhasin, D.K., Thapa, B.R. and Singh, K. (1999) Detection of Clostridium difficile Toxin by an Indigenously Developed Latex Agglutination Assay. Tropical Gastroenterology, 22, 33-35.

[25] Vaishnavi, C., Thapa, B.R., Thennarasu, K. and Singh, K. (2002) Faecal Lactoferrin Assay as an Adjunct to Clostridium difficile Diarrhea. Indian Journal of Pathology and Microbiology, 45, 69-73.

[26] Vishwanath, S., Singhal, A., D’Souza, A., Mukhopadhyay, C., Varma, M. and Bairy, I. (2013) Clostridium difficile Infection at a Tertiary Care Hospital in South India. Journal of the Association of Physicians of India, 61, 804-806.

[27] Holloway, K.A. (2011) Promoting the Rational Use of Antibiotics, Regional Health Forum WHO South East Asia Region. Volume 15, 122-130.

[28] Austin, D.J. and Anderson, R.M. (1999) Transmission Dynamics of Epidemic Methicillin-Resistant Staphylococcus aureus and Vancomycin-Resistant Enterococci in England and Wales. Journal of Infectious Diseases, 179, 883-891. http://dx.doi.org/10.1086/314682

[29] Cocanour, C.S. (2005) Best Strategies in Recurrent or Persistent Clostridium difficile Infection. Surgical Infections, 12, 235-239. http://dx.doi.org/10.1089/sur.2010.080 
[30] Dong, D., Zhang, L., Chen, X., Jiang, C., Yu, B., Wang, X. and Peng, Y. (2013) Antimicrobial Susceptibility and Resistance Mechanisms of Clinical Clostridium difficile from a Chinese Tertiary Hospital. International Journal of Antimicrobial Agents, 41, 80-84. http://dx.doi.org/10.1016/j.ijantimicag.2012.08.011

[31] Goudarzi, M., Goudarzi, H., Alebouyeh, M., Rad, M.A., Mehr, F.S.S., Mohammad, R.Z. and Mohammad, M.A. (2013) Antimicrobial Susceptibility of Clostridium difficile Clinical Isolates in Iran. Iranian Red Crescent Medical Journal, 15, 704-711. http://dx.doi.org/10.5812/ircmj.5189

[32] Vecchio, A.L. and Zacur, G.M. (2012) Clostridium difficile Infection: An Update on Epidemiology, Risk Factors and Therapeutic Options. Current Opinion in Gastroenterology, 28, 1-9. http://dx.doi.org/10.1097/MOG.0b013e32834bc9a9

[33] Sebaihia, M., Wren, B.W., Mullany, P., Fairweather, N.F., Minton, N., Stabler, R., Thomson, N.R., Roberts, A.P., Cerdeño-Tárraga, A.M., Wang, H., Holden, M.T., Wright, A., Churcher, C., Quail, M.A., Baker, S., Bason, N., Brooks, K., Chillingworth, T., Cronin, A., Davis, P., Dowd, L., Fraser, A., Feltwell, T., Hance, Z., Holroyd, S., Jagels, K., Moule, S., Mungall, K., Price, C., Rabbinowitsch, E., Sharp, S., Simmonds, M., Stevens, K., Unwin, L., Whithead, S., Dupuy, B., Dougan, G., Barrell, B. and Parkhill, J. (2006) The Multidrug-Resistant Human Pathogen Clostridium difficile Has a Highly Mobile, Mosaic Genome. Nature Genetics, 38, 779-786. http://dx.doi.org/10.1038/ng1830

[34] Spigaglia, P., Barbanti, F. and Mastrantonio, P. (2011) Multidrug Resistance in European Clostridium difficile Clinical Isolates. Journal of Antimicrobial Chemotherapy, 66, 2227-2234. http://dx.doi.org/10.1093/jac/dkr292

[35] Brazier, J.S. (2001) Typing of Clostridium difficile. Clinical Microbiology and Infection, 7, 428-431. http://dx.doi.org/10.1046/j.1198-743x.2001.00288.x

[36] Chong, P.M., Lynch, T., McCorrister, S., Kibsey, P., Miller, M., Gravel, D., Westmacott, G.R. and Mulvey, M.R., The Canadian Nosocomial Infection Surveillance Program (CNISP) (2014) Proteomic Analysis of a NAP1 Clostridium difficile Clinical Isolate Resistant to Metronidazole. PLOS ONE, 9, e82622. http://dx.doi.org/10.1371/journal.pone.0082622

[37] Peláez, T., Alcalá, L., Alonso, R., Rodriguez-Creixems, M., García-Lechuz, J. and Bouza, E. (2002) Reassessment of Clostridium difficile Susceptibility to Metronidazole and Vancomycin. Antimicrobial Agents and Chemotherapy, 46, 1647-1650. http://dx.doi.org/10.1128/AAC.46.6.1647-1650.2002

[38] Fernandez, A., Anand, G. and Friedenberg, F. (2004) Factors Associated with Failure of Metronidazole in Clostridium difficile-Associated Disease. Journal of Clinical Gastroenterology, 38, 414-418. http://dx.doi.org/10.1097/00004836-200405000-00005

[39] Peláez, T., Cercenado, E., Alcalá, L., Marín, M., Martin-Lopez, A., Martínez-Alarcón, J., Catalán, P., Sánchez-Somolinos, M. and Bouza, E. (2008) Metronidazole Resistance in Clostridium difficile Is Heterogeneous. Journal of Clinical Microbiology, 46, 3028-3032. http://dx.doi.org/10.1128/JCM.00524-08

[40] McFarland, L.V. (2005) Alternative Treatments for Clostridium difficile Disease: What Really Works? Journal of Medical Microbiology, 54, 101-111. http://dx.doi.org/10.1099/jmm.0.45753-0

[41] Pépin, J., Valiquette, L., Gagnon, S., Routhier, S. and Brazeau, I. (2007) Outcomes of Clostridium difficile-Associated Disease Treated with Metronidazole or Vancomycin before and after the Emergence of NAP1/027. The American Journal of Gastroenterology, 102, 2781-2788. http://dx.doi.org/10.1111/j.1572-0241.2007.01539.X

[42] Huang, H., Fang, H., Weintraub, A. and Nord, C.E. (2009) Distinct Ribotypes and Rates of Antimicrobial Drug Resistance in Clostridium difficile from Shanghai and Stockholm. Clinical Microbiology and Infection, 15, 1170-1173. http://dx.doi.org/10.1111/j.1469-0691.2009.02992.x

[43] Spigaglia, P. and Mastrantonio, P. (2004) Comparative Analysis of Clostridium difficile Clinical Isolates Belonging to Different Genetic Lineages and Time Periods. Journal of Medical Microbiology, 53, 1129-1136. http://dx.doi.org/10.1099/jmm.0.45682-0

[44] Tenover, F.C., Tickler, I.A. and Persing, D.H. (2012) Antimicrobial-Resistant Strains of Clostridium difficile from North America. Antimicrobial Agents and Chemotherapy, 56, 2929-2932.

[45] Collins, D.A., Hawkey, P.M. and Riley, T.V. (2013) Epidemiology of Clostridium difficile Infection in Asia. Antimicrobial Resistance and Infection Control, 2, 21. http://dx.doi.org/10.1186/2047-2994-2-21

[46] Borgmann, S., Jakobiak, T., Gruber, H., Reil, M., Schröder, H., Kist, M. and Sagel, U. (2010) Association of Ciprofloxacin Prescriptions to Outpatients to Clostridium difficile Infections. Euro Surveillance, 15, Article ID: 19479.

[47] Gerding, D.N. (2004) Clindamycin, Cephalosporins, Fluoroquinolones, and Clostridium difficile-Associated Diarrhea: This Is an Antimicrobial Resistance Problem. Clinical Infectious Diseases, 38, 646-648. http://dx.doi.org/10.1086/382084

[48] Loo, V.G., Poirier, L., Miller, M.A., Oughton, M., Libman, M.D., Michaud, S., Bourgault, A.M., Nguyen, T., Frenette, C., Kelly, M., Vibien, A., Brasssard, P., Fenn, S., Dewar, K., Hudson, T.J., Horn, R., René, P., Monczak, Y. and Dascal, A. (2005) A Predominantly Clonal Multi-Institutional Outbreak of Clostridium difficile Associated Diarrhea with 
High Morbidity and Mortality. New England Journal of Medicine, 353, 2442-2449. http://dx.doi.org/10.1056/NEJMoa051639

[49] Drudy, D., Goorhuis, B., Bakker, D., Kyne, L., van den Berg, R., Fenelon, L., Fanning, S. and Kuijper, E.J. (2008) Clindamycin-Resistant Clone of Clostridium difficile PCR Ribotype 027, Europe. Emerging Infectious Diseases, 14, 1485-1487. http://dx.doi.org/10.3201/eid1409.071346

[50] Mooyottu, S., Flock, G., Kollanoor-Johny, A., Upadhyaya, I., Jayarao, B.A. and Venkitanarayanan, K. (2005) Characterization of a Multidrug Resistant Clostridium difficile Meat Isolate. International Journal of Food Microbiology, 192, 111-116. http://dx.doi.org/10.1016/j.ijfoodmicro.2014.10.002 